\title{
REALIZAÇÕES VARIÁVEIS DE VOGAIS TÔNICAS EM PORTO ALEGRE (RS): DITONGAÇÃO OU INGLIDING?
}

\author{
THE VARIATION OF STRESSED VOWELS IN PORTO \\ ALEGRE (RS): DIPHTHONGISATION OR INGLIDING?
}

\author{
Elisa Battisti \\ Universidade Federal do Rio Grande do Sul, Porto Alegre, RS, Brasil
}

Resumo: O presente artigo revisa a proposta de Bisol $(1989,1994,2012)$ sobre a existência de verdadeiros e falsos ditongos em português, para definir se a realização vocálica variável de vogais tônicas (né néah, aí aíah, tudo tuahdo) no falar de Porto Alegre (RS) é ditongação. A revisão sugere que a realização tenha representação subjacente monofonêmica, como nos ditongos falsos. Contudo, a oitiva de entrevistas sociolinguísticas mostra que o processo não é a ditongação assimilatória de Bisol. A análise acústica de dados prototípicos revela que há aumento na duração dessa realização. Há centralização da porção final da realização vocálica, o que é compatível com ingliding.

Palavras-chave: variação de vogais tônicas; Português Brasileiro; ditongação; ingliding; Leda Bisol.

Abstract: In this paper, the hypothesis by Bisol $(1989,1994,2012)$ of a distinction between true and false diphthongs in Portuguese is reviewed in order to make a decision about the nature of the variable process which targets stressed vowels (né néah 'isn't it?', aí aíah 'then; there', tudo tuahdo 'everything') in the speech of Porto Alegre (RS). The review suggests that the process results in false diphthongs. The auditory analysis of sociolinguistic interviews shows that the process is not assimilatory diphthongisation. The acoustic analysis of prototypical speech data shows an increase in the duration of those vowels, as well as the centralization of their final portion, attesting that the process is ingliding.

Keywords: variation of stressed vowels; Brazilian Portuguese; diphthongisation; ingliding; Leda Bisol.

\section{Introdução}

A hipótese de Leda Bisol (1989, 1994, 2012) de que, em português, ditongos decrescentes verdadeiros (não-derivados) distinguem-se, em termos fonológicos, de ditongos decrescentes falsos (derivados) vem inspirando análises desde sua proposição. Resultado de pesquisa pós-doutoral realizada na Universidade de Stanford, em 1988, fundamenta-se na Teoria da Sílaba (SELKIRK, 1982; CLEMENTS e KEYSER, 1983; HULST, 1984), linha da Fonologia Autossegmental (GOLDSMITH, 1976), e corresponde à ideia de que ditongos como em leite, grau, boina, verdadeiros, são a combinação de duas vogais subjacentes, uma das quais se torna semivogal por silabação. Já ditongos como em peixe, caixa, feira, ouro, homem, falsos, sujeitos à redução variável (peixe $\sim$ pexe, caixa $\sim$ caxa, feira $\sim$ fera, ouro $\sim$ oro, homem $\sim$ home), têm uma só vogal na subjacência, a semivogal é derivada por regra assimilatória. 
Neste artigo, parte-se da hipótese de Bisol para, com o exame de dados de Porto Alegre (RS), verificar a possibilidade de conceber como ditongação (formação de ditongos falsos) o processo variável que dá origem a realizações peculiares de vogais em sílabas tônicas no português brasileiro falado nessa comunidade. Assim fazendo, discutiremos uma das contribuições de Leda Bisol à pesquisa sobre fonologia do português.

As realizações variáveis em questão estão comumente presentes na concepção estereotipada da fala do "magrão" porto-alegrense, de quem ocorrências como né néah, aí aíah, tudo tuahdo são exemplos. Nelas, as vogais grifadas são eventualmente percebidas como longas, manhosas, preguiçosas $^{2}$, arrastadas ${ }^{3}$, afetadas ${ }^{4}$. Em termos labovianos (LABOV, 1972), essas realizações vocálicas parecem ser, a um só tempo, estereótipos (imitadas por pessoas de fora da comunidade), marcadores sociais (compõem um estilo), indicadores sociais (de classe social, por exemplo). São, portanto, objeto relevante a estudos sociolinguísticos, a merecer análise de regra variável, estudos de atitude, identidade e estilo.

Análises como essas, no entanto, requerem saber, antes de tudo e em termos estruturais, de que processo se trata, que propriedades e restrições estão nele envolvidas. Tais realizações variáveis são sistemáticas? Que vogais são alvo e em que contexto são alteradas? Em termos acústicos, em que consistem? Essas são as questões a serem respondidas neste artigo ${ }^{5}$.

Hayes $(2009$, p. 59) trata como ditongação o processo similar que se aplica a /æa/ antes de nasal, no idioma inglês: $m[\boldsymbol{x}] n \sim m[\boldsymbol{\varepsilon} \boldsymbol{\theta}] n$ 'homem',

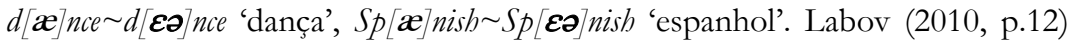
chama de ingliding a alteração de vogais $\operatorname{curtas}^{6}$ que geralmente alonga as baixas e faz emergir o glide [ə] em vogais médias e altas, resultando em formas

\footnotetext{
${ }^{1}$ Termo equivalente a descolado, definido no Dicionário Honaiss da Lingua Portuguesa (HOUAISS e VILLAR, 2009, p.635) como pessoa "que revela desembaraço e iniciativa; [...] esperto, safo".

2 Postagem datada de 20 ago. 2011. Disponível em: http://www.formspring.me/melilin/q/ 229367389907586791. Acesso em: 10 maio 2013.

${ }^{3}$ Postagem datada de 2 mar. 2010. Disponível em: http://www.cuca.in/manias/o-pior-sotaquedo-mundo/ Acesso em: 10 maio 2013.

${ }^{4}$ Postagem datada de 23 out. 2011. Disponível em:

http://divagabunda.blogspot.com.br/2009/06/o-sotaque-do-porto-alegrense-afetado.html

Acesso em: 10 maio 2013.

${ }^{5}$ Uma primeira versão do trabalho foi apresentada oralmente no Seminário de Teoria e Análise Linguística, atividade do PPG-Let da UFRGS, em 19 jun. 2013, com o título Alongamento vocálico e ditongação no português falado em Porto Alegre: primeiras indagações, em co-autoria com Rogério Tomás de Carvalho, bolsista PROBIC-Fapergs, e Reiner Vinicius Perozzo, doutorando em Estudos da Linguagem do PPG-Let-UFRGS. Ao primeiro, devo a oitiva de entrevistas sociolinguísticas e o levantamento de dados para a análise acústica. Ao segundo, a análise acústica dos primeiros dados. Aos dois, meus agradecimentos.

${ }^{6} \mathrm{O}$ sistema vocálico do inglês opõe vogais curtas a longas. Juntamente com o conjunto de ditongos, conta com 16 oposições ou unidades com valor distintivo.
} 
ditongadas cuja porção final é centralizada (fa[a]ther 'pai', bou[ $[\mathbf{\theta}] g h t$ 'comprou, comprado').

Nosso estudo mostrará que, nas realizações vocálicas portoalegrenses em questão, não se verificam condicionamentos segmentais específicos, como o de consoantes nasais na ditongação de /æ/no idioma inglês, ou o de $/ \mathrm{S}, \int, 3, \mathrm{r} /$ na formação de ditongos falsos em português, como veremos ao discutir a proposta de Leda Bisol. Há alongamento das vogais em sílabas tônicas, aparentemente em final de frase fonológica e de enunciado, e centralização da porção final da realização vocálica. É ingliding o processo gerador das realizações vocálicas peculiares ao falar de Porto Alegre, e não a ditongação assimilatória variável caracterizada por Bisol.

Para tanto, partiremos da revisão e discussão de Bisol (1989, 1994, 2012), de que se destacam, respectivamente, a representação dos ditongos decrescentes verdadeiros, como a combinação de duas vogais subjacentes, e dos ditongos falsos, com uma só vogal; a análise da formação de ditongos por assimilação de traço, no contexto de $/ \mathrm{S}, \int, 3 /$, e por expansão de nó ${ }^{7}$, no contexto de / $/$. Depois, apresentaremos a metodologia deste estudo, que inclui uma primeira exploração de dados de fala de informantes de Porto Alegre, utilizando-se entrevistas do $\mathrm{VARSUL}^{8}$, e uma análise acústica preliminar com o Praat ${ }^{9}$, de dados de um falante prototípico. Os resultados são discutidos com base na abordagem integrada de Fonologia e Fonética de Clements e Hertz (1996).

\section{A representação fonológica dos ditongos do português por Bisol (1989, 1994, 2012)}

Examinar as propostas de Bisol para a representação dos ditongos em português é explorar tanto a análise de dados em si, quanto os modelos teóricos por ela seguidos, avanços da Teoria Fonológica a seu tempo.

A hipótese da autora de que há, em português, verdadeiros e falsos ditongos é motivada pela realização invariante dos ditongos decrescentes da

7 Nó Cavidade Oral (CO), conforme a representação da estrutura interna do segmento pela
Geometria de Traços na proposta de Clements e Hume (1995).
8 VARSUL é sigla de Variação Linguística na Região Sul do Brasil, nome de um projeto
desenvolvido pela UFRGS, UFSC, UFPR e PUCRS que, desde 1988, volta-se à investigação das
variedades de português de comunidades de fala socioculturalmente representativas do Sul do
Brasil. De seu acervo de entrevistas, denominado Banco de Dados VARSUL, fazem parte 24
entrevistas de informantes de Porto Alegre, além de 264 outras, das demais 11 comunidades
investigadas. Mais informações em: http://www.varsul.org.br/. Acesso em: 27 ago. 2013 .
9 Praat é o nome de um programa computacional para análise fonética acústica desenvolvido pelos
professores e foneticistas Paul Boersma e David Weenink, da Universidade de Amsterdam. Mais
informações e download gratuito do programa em: http://www.fon.hum.uva.nl/praat/. Acesso em:
27 set. 2013 . 
Língua Portuguesa, exceto ai, ei, ou, que podem ser reduzidos a vogais simples em certos contextos. Vejam-se os exemplos em 1(a), sem redução, e em 1(b), com redução, que criam a alternância entre ditongo e vogal simples, conforme Bisol (1989, p.190):

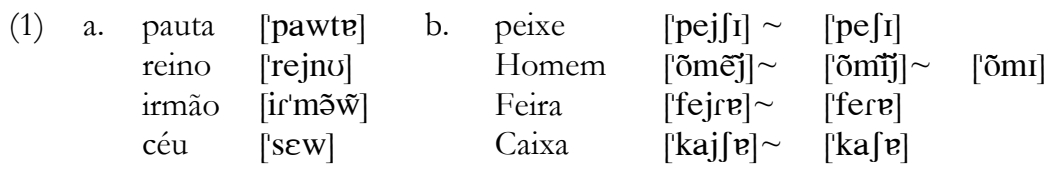

O estatuto fonológico dos ditongos como os de 1(a) pode ser comprovado em pares mínimos de vocábulos com ditongo e com vogal simples, conforme Bisol (1989, p. 190):

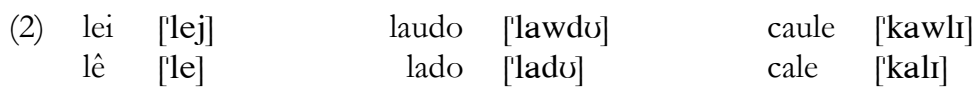

A alternância entre ditongo e vogal simples, exemplificada em 1(b), sugere à autora que o ditongo seja meramente fonético, já que o apagamento do glide não causa diferença de significado. Os dados sugerem que o ditongo seja derivado, ou seja, que haja uma só vogal na representação fonológica.

A Teoria da Sílaba e a ideia fundamental de que essa unidade prosódica tenha uma estrutura interna, de constituintes hierarquicamente organizados em tiers ${ }^{10}$, possibilita a Bisol representar essa diferença estrutural entre ditongos verdadeiros e falsos. Em (3), veem-se os constituintes silábicos nos tiers da rima (dos constituintes onset e rima), prosódico (dos espaços temporais ocupados pelos constituintes) e melódico (dos traços que definem os segmentos), conforme Bisol (1989, p. 186):

(3)

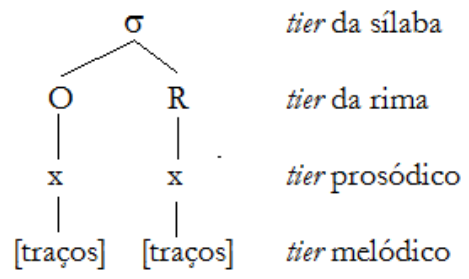

Os ditongos verdadeiros apresentam duas posições (do tier prosódico) associadas à rima (tier da rima), os ditongos falsos, uma só, como 4(a) e 4(b) representam, respectivamente, conforme Bisol (1989, p.190):

10 'Camada' é um equivalente do português para tier, vocábulo da língua inglesa. 
(4) a

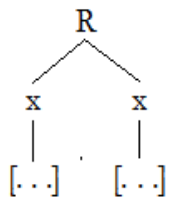

b.

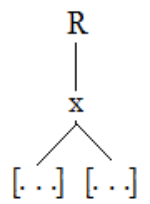

Às duas posições no tier prosódico da rima de ditongos verdadeiros (4a) associam-se duas vogais. À única posição no tier prosódico de ditongos falsos (4b) associa-se uma vogal. O glide surge no tier melódico por processos assimilatórios, mas associa-se a essa única posição do tier prosódico.

A pergunta decorrente dessa interpretação, geralmente aceita pelos fonólogos brasileiros, diz respeito aos processos assimilatórios que fazem surgir o glide e, com ele, os ditongos falsos: que processos são esses? A resposta começa a ser enunciada já em Bisol (1989), mas se completa apenas nos trabalhos de 1994 e 2012.

A autora observa que, no contexto de consoante palatal, o glide pode ser tanto apagado quanto inserido, sem que isso afete o significado da palavra. Fornece os seguintes exemplos (BISOL, 1989, p.191):

$$
\begin{aligned}
& \text { Apagamento } \\
& \text { peixe }\left[\operatorname{pej} \int \mathrm{r}\right] \sim\left[\operatorname{pe} \int \mathrm{r}\right] \\
& \text { seixo }\left[\operatorname{sej} \int v\right] \sim\left[\operatorname{se} \int u\right]
\end{aligned}
$$
b. Acréscimo vexame [ve' 'ว̃mI] [vej']ว̃mI] faxina [fa' Jine] [ [faj']ine]

Esse fato sugere à autora que o glide se forma no tier melódico, pelo espraiamento do traço de altura da palatal. Vocábulos como peixe e vexame teriam, portanto, a mesma estrutura profunda (/pe Je/ e / ve Jame/), com rima associada a uma só posição no tier prosódico.

A representação desse processo assimilatório como espraiamento de traço, conforme o previsto pela Fonologia Autossegmental, ganha consistência em Bisol (1994), já na linha de Clements (1991): expressa-se a altura da vogal com três traços de abertura (aberto 1, 2, 3). Esses e os demais traços fonológicos são agrupados hierarquicamente em nós. Consoantes e vogais são definidas por traços fonológicos comuns (coronal, dorsal, labial e anterior), agrupados em nós distintos [Pontos de Articulação de Consoantes (PC), nas consoantes, Pontos de Articulação de Vogais (PV), nas vogais]. A consoante palatal é complexa, no sentido de que, além do traço de consoante [coronal], seu nó PC tem um ramo vocálico. É justamente esse ramo vocálico que espraia para a vogal precedente, sem traços de abertura dependentes, mas assumindo [-ab $\left.1 \begin{array}{lll}2 & 3\end{array}\right]$ na manifestação fonética, o que leva à formação do glide e, assim, à 
criação dos ditongos falsos. É o que se vê em (6), conforme Bisol (1994, p. 130) $)^{11}$ :

\section{(6) Espraiamento e epêntese}

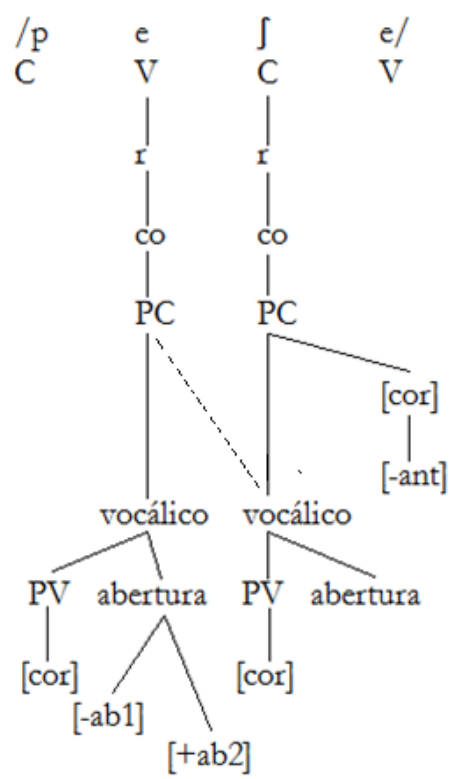

Bisol (1994) representa ainda, nessa mesma linha, a ditongação em sílaba acentuada final fechada por /S/, mesmo que essa consoante de travamento não se manifeste como consoante palatal: mêis, feiz, tráis, rapaiz. A hipótese da autora é a de que o arquifonema /S/ possua um nó vocálico que, espraiado, cria o glide tanto nos dialetos em que ele se manifesta como palatal, quanto em dialetos em que se manifesta como coronal. Nesse último caso, em que o ramo vocálico do arquifonema espraia para a vogal, é desligado do arquifonema e surge o glide, como se vê em (7), representação adaptada de Bisol (1994, p. 137):

${ }^{11} \mathrm{O}$ espraiamento é representado pela linha pontilhada. As letras $\mathrm{C} \mathrm{e} \mathrm{V}$ maiúsculas são as iniciais de consoante e vogal, respectivamente, e equivalem a " $x$ " na representação silábica em tiers usada por Bisol (1989). A letra " $\mathrm{r}$ " minúscula é a inicial de raiz, "co", as iniciais de cavidade oral. 
(7) Ditongo falso antes de coda /S/ em sílaba tônica

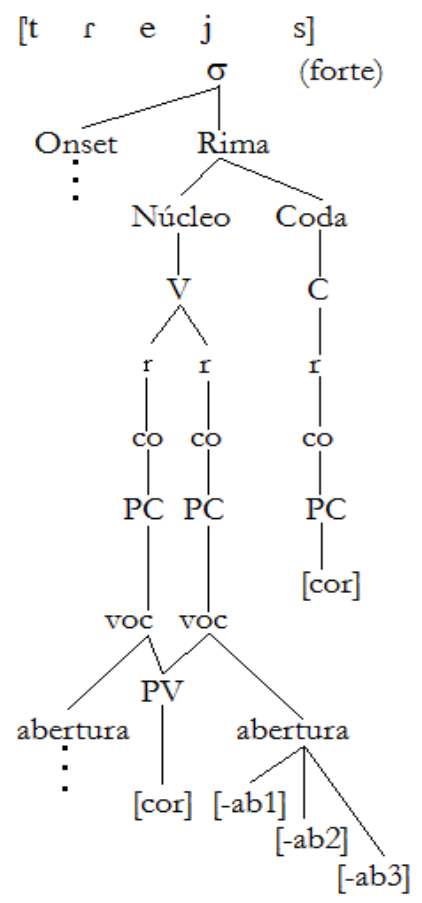

Ainda na linha autossegmental e dando conta do contexto /r/seguinte, Bisol (2012) entende que a natureza vocálica das líquidas é o desencadeador da ditongação. Em termos de representação, isso equivale a dizer, então, que o nó CO (cavidade oral) inteiro espraia, criando-se assim o glide. A diferença entre essa e a análise anterior está na constatação de que a expansão de vocálico cria segmentos complexos, a de $\mathrm{CO}$, um novo segmento. Assim, se todas as consoantes que desencadeiam o processo assimilatório criador dos ditongos falsos têm o nó vocálico e praticamente a mesma estrutura interna, é possível propor, como faz a autora, que o glide se cria pela expansão do nó $\mathrm{CO}$ em todos os casos de ditongação assimilatória, o que Bisol (2012, p. 64) representa pelo esquema em (8): 
(8) Formação do ditongo variável

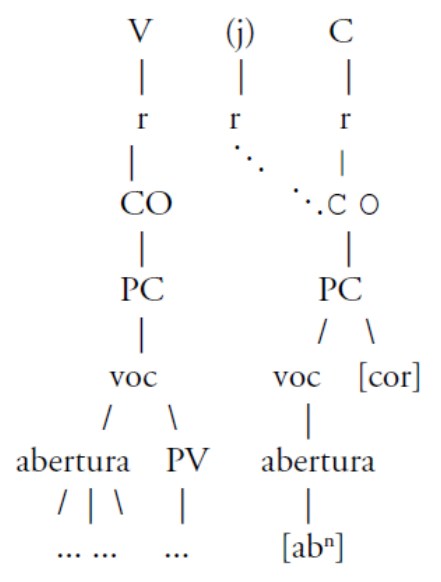

A distinção entre ditongos verdadeiros e falsos inspirou estudos subsequentes de muitos pesquisadores brasileiros, entre eles, os orientandos da própria Leda Bisol. Com dados do VARSUL e análise de regra variável, destacam-se o estudo de monotongação de Cabreira (1996) e de ditongação de Mello (1994), Leiria (1995) e Tasca (2005). Esses estudos controlam o papel de variáveis linguísticas e sociais no condicionamento dos processos, fundados na ideia de Bisol de que a criação do glide deve-se em boa medida ao contexto segmental seguinte e de que a monotongação apaga um segmento derivado, inexistente na representação subjacente.

$\mathrm{O}$ presente estudo lida com um fenômeno que, em termos de percepção, parece formar ditongo, um ditongo decrescente com glide centralizado, similar ao que Labov (2010) registra ortograficamente como ah. Diferentemente da ditongação assimilatória abordada por Bisol, não há estudos sobre a formação variável de ditongos decrescentes com glide centralizado no português de Porto Alegre. Embora haja manifestações valorativas sobre essa realização vocálica, como referido na introdução deste artigo, não há ainda análise linguística sobre o tema. Vem daí a justificativa para a realização deste estudo: dar o primeiro passo, o da caracterização estrutural do processo, para futuras investigações sociolinguísticas sobre esse tipo de realização.

A revisão dos trabalhos de Bisol permite-nos assumir a hipótese de que, nessas realizações variáveis, como na formação de ditongos falsos em geral, há uma só vogal na subjacência. O glide se cria ou por influência do contexto fonológico vizinho, ou por outras razões que resta descobrir. Como se verá na metodologia, uma primeira parte deste estudo orienta-se pela 
hipótese de Bisol, a da formação assimilatória de ditongos, e busca identificar segmentos seguintes à vogal que possam desencadear o processo. A segunda parte, com apoio de recursos de análise fonética acústica, busca caracterizar o fenômeno vocálico sob investigação.

\section{Metodologia}

Para cumprir o objetivo de verificar se há algum contexto (consoante seguinte ou ausência de consoante) em que as realizações ditongadas em questão predominem, assim identificando elementos que confiram sistematicidade ao processo, realiza-se a oitiva de 24 entrevistas com informantes de Porto Alegre, por meio do VARSUL. Essas entrevistas, que datam do início dos anos 1990 e versam sobre temas do cotidiano, têm cerca de 50 minutos de duração. Os informantes são homens e mulheres, distribuídos em dois grupos etários (menos de 50 anos, mais de 50 anos de idade) e três níveis de escolaridade (primeiros anos do Ensino Fundamental, Ensino Fundamental completo, Ensino Médio). A oitiva busca identificar as vogais tônicas que sofrem ditongação e o contexto fonológico seguinte em que o fenômeno ocorre.

Cumpre-se o objetivo de caracterizar foneticamente as realizações ditongadas por meio de análise acústica; para tanto, utiliza-se o programa computacional Praat. $\mathrm{O}$ estudo busca os valores médios de duração e de $\mathrm{F}_{1}$, $\mathrm{F}_{2}{ }^{12}$ das realizações. Tendo como inspiração Labov (2010, p. 207), que considera um determinado informante da Filadélfia como o protótipo de um padrão de mudança fônica, toma-se K.S., mulher porto-alegrense de 55 anos, comunicadora de rádio ${ }^{13}$, como um protótipo da realização investigada. Sua fala foi gravada em uma palestra ${ }^{14}$ ocorrida na UFRGS, em maio de 2013, com um gravador digital GH-609. De sua fala, levantam-se os dados analisados acusticamente, recortados do áudio da palestra com o programa Sound Forge 915. Para este artigo, analisam-se quatro realizações, duas delas do vocábulo

\footnotetext{
${ }^{12} \mathrm{~F}_{1}, \mathrm{~F}_{2}$ e $\mathrm{F}_{3}$ são formantes vocálicos, ou "zonas de frequência intensificadas pelas cavidades de ressonância de acordo com as diferentes configurações assumidas pelo trato vocal" (SILVA, 2011, p.120). Com a medida em hertz $(\mathrm{Hz})$ de $\mathrm{F}_{1}$, verifica-se a altura da vogal; com a medida de $\mathrm{F}_{2}$, a anterioridade/posterioridade.

${ }^{13} \mathrm{Na}$ valoração intuitiva das realizações vocálicas ditongadas, referida na Introdução deste artigo, é recorrente a menção a comunicadores de rádio e apresentadores de televisão como sujeitos cuja fala tem exemplos dessas realizações.

${ }^{14}$ Embora K.S. não tenha assinado um Termo de Consentimento Livre e Esclarecido, ela foi contatada dias antes pela autora do presente artigo, para esclarecimentos sobre a pesquisa que estava sendo realizada (objeto, propósitos). Pediu-se permissão para gravar a palestra, permissão essa concedida pela comunicadora.

15 Sound Forge é um programa computacional que edita e cria áudio digital. Disponível em: http://www.baixaki.com.br/download/sony-sound-forge-pro.htm. Acesso em: 29 set. 2013.
} 
ibope, para medir a duração, as outras duas, lota e né, para as medidas de $\mathrm{F}_{1}$ e $\mathrm{F}_{2}$.

\section{Apresentação e discussão dos resultados}

A oitiva das vinte e quatro entrevistas do VARSUL fez uma primeira revelação surpreendente: apenas um dos informantes, um jovem, produz alongamento e ditongação das vogais. Os demais vinte e três informantes podem eventualmente alongar as vogais, sem, contudo, ditongá-las. Tanto o alongamento quanto a ditongação parecem ocorrer predominantemente em final de enunciado ([Tava muito tranquilo]u) ou de frase fonológica ([Um mêss $\left.]_{\phi}\left[\text { de cas } \underline{\mathbf{a}} \mathrm{da}_{\phi}\right]_{\phi}[\text { e se separo }(\mathrm{u})]_{\phi}\right)$.

Esta análise também revelou que todas as sete vogais tônicas são alvo da ditongação em questão: /i/ ainda, aqui, dentista; /e/ vocês, cabeça, lembra, apê; $/ \varepsilon /$ até, bicicleta, empresta, certo; /a/ babá, bacana, anda; / / vó, gosta, nota, acorda; /o/ vô, ponto; /u/ tudo, luz, fundo. Nos exemplos, nota-se que a ditongação pode afetar as vogais seguidas de /S/, $/ \mathrm{N} /{ }^{16}, / \mathrm{R} /$ e vogais em sílabas abertas. Não se pôde verificar o papel de /L/ seguinte porque o sujeito ditongador, como boa parte dos gaúchos hoje, vocaliza a lateral em coda, o que por si só dá origem a uma realização ditongada.

As generalizações que se podem tecer da oitiva são as de que (i) o fenômeno é relativamente recente no falar de Porto Alegre. À época em que as entrevistas do VARSUL foram feitas, o processo provavelmente estava presente apenas na fala dos mais jovens, que atualmente devem ter entre $50 \mathrm{e}$ 60 anos de idade; (ii) não há uma vogal-alvo específica, tampouco um contexto fonológico seguinte específico para a ditongação. Talvez uma análise de regra variável tivesse revelado que um tipo de consoante em coda, ou sílaba aberta, mais do que outro contexto, tenderia a promover a ditongação. Mas esse nosso primeiro diagnóstico, do modo como foi feito, revela os possíveis alvos e os potenciais gatilhos da regra, não seu peso relativo: a ditongação pode afetar todas as vogais tônicas e em qualquer contexto fonológico seguinte, o que leva a descartar a hipótese de ditongação assimilatória na linha de Bisol (1989, 1994, 2012), embora se mantenha a ideia da autora de que haja uma só vogal na representação subjacente. A que se deve, então, a ditongação percebida de oitiva?

A análise acústica trouxe uma resposta a essa pergunta. As duas ocorrências do vocábulo ibope, enunciadas por nossa falante prototípica, uma

\footnotetext{
${ }^{16}$ No português de Porto Alegre, como em outras variedades de português do Sul do Brasil, não se realizam vogais médias baixas antes de consoante nasal, razão pela qual não se pôde verificar ditongação de $/ \varepsilon /$ e $/ \rho /$ no contexto de $/ N /$ seguinte.
} 
percebida (de oitiva) sem ditongação da vogal tônica, outra com ditongação, mostraram que a duração tem papel: na realização sem ditongação, a vogal teve a duração de 90 ms (milissegundos); na realização com ditongação, de 335 ms. Se, em análises posteriores, o papel da duração se confirmar, teremos aí o gatilho da regra: a emissão das vogais tônicas com maior duração desencadearia a ditongação, não o contexto fonológico seguinte, prioritariamente. A maior duração, por sua vez, seria propiciada pela posição final de frase ou de enunciado, afirmação que, no entanto, ainda não se pode sustentar, porque carece ser investigada.

$\mathrm{E}$ em que consiste o glide das realizações ditongadas sob investigação? Para responder a essa pergunta, analisaram-se acusticamente as realizações vocálicas ditongadas de né, na sequência "[...] basicamente isso, né?", e de lota, na sequência “[...] Roberto Carlos lota”. O espectrograma ${ }^{17}$, em (9), é o da realização ditongada em né. Nele se vê, principalmente nas porções destacadas ${ }^{18}$, a mudança de qualidade vocálica:

(9) Espectrograma da realização vocálica ditongada em né

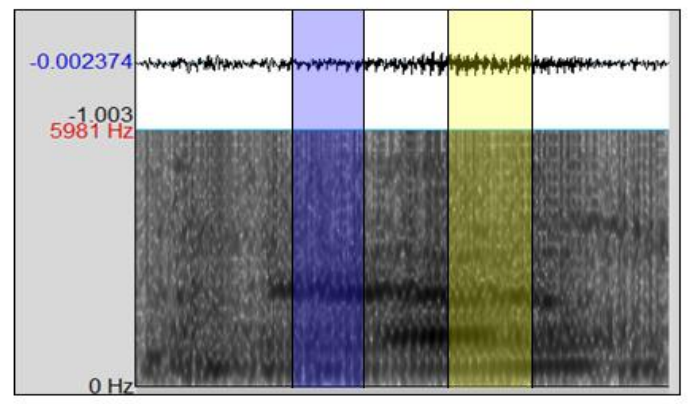

Os valores médios dos formantes vocálicos, nas porções destacadas, como também sua duração, são bastante reveladores. Veja-se o Quadro 1:

\footnotetext{
17 A gravação foi feita em um auditório, não em uma cabine com isolamento acústico, o que é geralmente exigido para a obtenção de dados a serem submetidos à análise acústica. Por isso, há ruído de fundo, o que 'escurece' o espectrograma. Entendemos, no entanto, que isso não invalide a análise, uma vez que se consegue captar a alteração vocálica em questão e, o mais importante, em dados de fala real, nas mesmas condições de produção-recepção disponíveis aos usuários numa situação de uso efetivo da linguagem.

18 As porções destacadas correspondem aos segmentos da realização vocálica percebidos mais claramente como distintos pelo seu padrão formântico e, também, auditivamente.
} 
Quadro 1 - Médias formânticas e duracionais da realização ditongada de né

\begin{tabular}{|c|c|c|}
\hline & Porção inicial: $[\varepsilon]$ & Porção final: glide \\
\hline $\mathrm{F}_{3}$ & $1897,571 \mathrm{~Hz}$ & $1934,4340 \mathrm{~Hz}$ \\
\hline $\mathrm{F}_{2}$ & $1522,3989 \mathrm{~Hz}$ & $1355,7728 \mathrm{~Hz}$ \\
\hline $\mathrm{F}_{1}$ & $507,588 \mathrm{~Hz}$ & $768,183 \mathrm{~Hz}$ \\
\hline & Dur. $0,085 \mathrm{~s}$ & Dur. $0,084 \mathrm{~s}$ \\
\hline
\end{tabular}

Fonte: Da autora

A porção inicial e a porção final da realização vocálica têm quase a mesma duração ( $85 \mathrm{~ms}$ e $84 \mathrm{~ms}$, respectivamente). Considerando-se o valor médio de $\mathrm{F}_{2}$, que é referente à anterioridade/posterioridade da vogal, e também o fato de que, quanto mais baixo o valor de $\mathrm{F}_{2}$, mais posterior é a vogal, verifica-se posteriorização vocálica da primeira para a segunda porção, pois o valor médio de $F_{2}$ diminui $(1522,3989 \mathrm{~Hz}$ na primeira porção, $1355,7728 \mathrm{~Hz}$ na segunda).

Considerando-se o valor médio de $F_{1}$, relativo à altura da vogal (quanto mais baixa a vogal, mais alto o valor de $\mathrm{F}_{1}$ ), constata-se abaixamento vocálico da primeira para a segunda porção, pois o valor médio de $F_{1}$ aumenta (507,588 Hz no primeiro segmento, 768,183 Hz no segundo).

Os valores de $F_{1}$ e $F_{2}$ da porção final da realização vocálica parecem compatíveis com $[\mathfrak{e}]$, um segmento posteriorizado e, assim, centralizado, se comparado a $[\varepsilon]$, também mais baixo do que $[\varepsilon]$. Em Silva (2011, p. 121), há a figura da plotagem em um gráfico dos valores de $F_{1}$ e $F_{2}$ de várias realizações das sete vogais orais do português brasileiro. Nela, marcamos com um * o ponto da área vocálica em que se situaria o segmento vocálico na porção final da realização em questão:

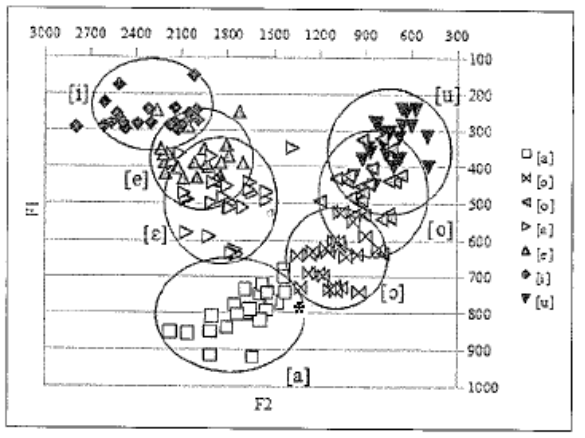

Figura 1 - Localização de [e] (*) num gráfico de F1 e F2 representativo da área das sete vogais fonêmicas do português 
Interessantemente, a porção final da realização vocálica tônica de lota apresenta quase os mesmos valores médios de $F_{1}$ e $F_{2}$, como veremos a seguir. Em (10) está o espectrograma dessa realização, no qual se visualiza a mudança de qualidade vocálica no contraste entre a primeira e a segunda porções destacadas.

(10) Espectrograma da realização vocálica ditongada em lota

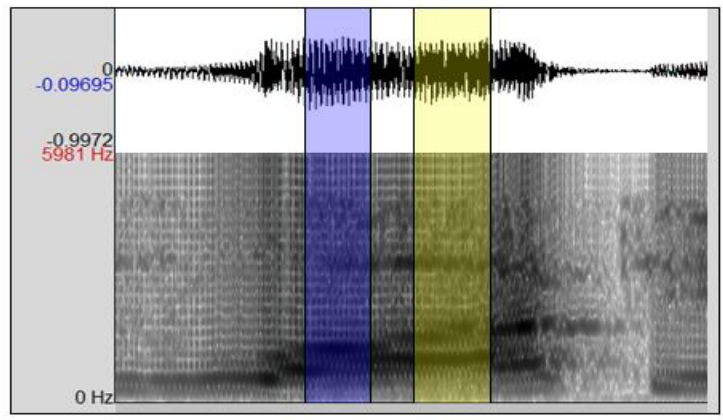

No Quadro 2, estão os valores médios dos formantes vocálicos nas porções destacadas, como também sua duração:

Quadro 2 - Médias formânticas e duracionais da realização ditongada de lota

\begin{tabular}{|c|c|c|}
\hline & Porção inicial: $[0]$ & Porção final: [e] \\
\hline $\mathrm{F}_{3}$ & $2488,1616 \mathrm{~Hz}$ & $2462,9083 \mathrm{~Hz}$ \\
\hline $\mathrm{F}_{2}$ & $1018,4945 \mathrm{~Hz}$ & $1361,655 \mathrm{~Hz}$ \\
\hline $\mathrm{F}_{1}$ & $686,730 \mathrm{~Hz}$ & $795,564 \mathrm{~Hz}$ \\
\hline & Dur. $0,058 \mathrm{~s}$ & Dur. $0,077 \mathrm{~s}$ \\
\hline
\end{tabular}

Fonte: Da autora

Novamente, as medidas de duração das duas porções da realização vocálica são comparáveis: $58 \mathrm{~ms}$ a porção inicial, $77 \mathrm{~ms}$ a porção final. O valor médio de $\mathrm{F}_{2}$ aumenta, o que mostra a anteriorização (centralização) na porção final: passa de $1018,4945 \mathrm{~Hz}$, na primeira porção, para 1361,655 Hz, na segunda. 
Considerando-se o valor médio de $F_{1}$, relativo à altura da vogal (quanto mais baixa a vogal, mais alto o valor de $\mathrm{F}_{1}$ ), constata-se abaixamento vocálico da primeira para a segunda porção, pois o valor médio de $F_{1}$ aumenta (686,730 Hz, no primeiro segmento, $795,564 \mathrm{~Hz}$, no segundo).

Observa-se que, também em lota, a porção final da realização vocálica apresenta valores médios de $\mathrm{F}_{1}$ e $\mathrm{F}_{2}$ compatíveis com [e]. Isso confirma que essa realização não é fortuita ou aleatória e talvez explique o fato de, intuitiva e sistematicamente, os falantes perceberem um "a" no final da realização vocálica.

A análise acústica confirmou, então, que, a despeito da qualidade da vogal nuclear $([\varepsilon]$ em né, $[0]$ em lota), a porção final da realização vocálica ocorre consistentemente como uma vogal centralizada, mais baixa do que a vogal-núcleo. Em vez de essa porção anteriorizar-se e elevar-se, como ocorre no padrão de ditongação analisado por Bisol $(1898,1994,2012)$ em contexto de /S/ (em que dez, voz, traz alternam com deiz, voiz, traiz, por exemplo), há sua centralização e abaixamento.

$\mathrm{Na}$ introdução do ANAE (The Atlas of North American English, Atlas do Inglês Norte-Americano), Labov, Ash e Boberg (2006) explicam que esse tipo de realização vocálica, chamada ingliding, distingue-se da ditongação que cria glides altos justamente porque seu aspecto caracterizador não é a elevação ou abaixamento da língua, mas principalmente seu distanciamento dos pontos periféricos (anterior e posterior), no espaço vocálico, o que é captado na análise acústica pelos valores de $\mathrm{F}_{2}$. Daí a identificação do ingliding como o processo fonético que, em inglês, cria centering diphthongs (ditongos centralizados), o que parece ocorrer também nas realizações vocálicas sob investigação ${ }^{19}$.

Clements e Hertz (1996) identificam a possibilidade de ingliding fonético em núcleos curtos do inglês, num estudo sobre núcleos vocálicos curtos, longos e ditongais, conforme a abordagem integrada de Fonética e Fonologia, de sua autoria,. Nessa proposta, em que a estrutura fonológica e a estrutura fonética acústica formam um sistema representacional único e uniforme, o ingliding é concebido como uma realização ditongada que envolve dois estágios estacionários ${ }^{20}$ (steady states, em inglês). Porque não determinado coarticulatoriamente, o ingliding resulta numa estrutura de contorno intrínseca ao fone. Em (11) e (12), reproduzem-se, respectivamente, um diagrama

\footnotetext{
${ }^{19}$ Os autores referem o condicionamento do ingliding pelo contexto fonológico seguinte, o que não se constatou no presente estudo. No entanto, devido a seu caráter exploratório inicial e a necessidade de aprofundar a análise acústica, essa nossa constatação poderá ser revisada em estudos futuros.

${ }^{20}$ Estágio estacionário, ou estrutura formântica de estágio estacionário, é o intervalo de tempo durante o qual os articuladores mantêm uma configuração do trato oral apropriada para a produção do segmento.
} 
esquemático dos movimentos formânticos do ingliding no vocábulo bid (oferta), e a correspondente representação em múltiplos tiers proposta pelos autores, conforme Clements e Hertz (1996, p. 11-12)

(11) Esquema dos movimentos formânticos do ingliding em bid

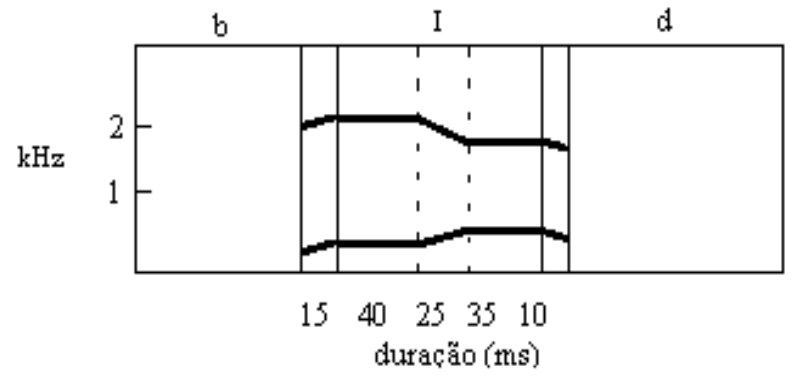

No esquema (11), percebe-se que a duração dos dois estágios estacionários, ou porções da realização vocálica, como vínhamos denominando neste trabalho, é equivalente: $40 \mathrm{~ms}$ e $35 \mathrm{~ms}$. Há um declínio de $\mathrm{F}_{2}$ de um para outro estágio, o que indica posteriorização/centralização, e uma elevação de $\mathrm{F}_{1}$, que indica abaixamento vocálico. Guardada a diferença de qualidade da vogal-núcleo, esse padrão formântico parece similar ao que verificamos na realização vocálica de né em nosso estudo.

Na proposta de Clements e Hertz (1996), a abordagem integrada da Fonologia e da Fonética, as representações de traços parcialmente especificados organizados em tiers no nível fonológico da gramática, são transferidas automaticamente para o nível fonético, que fornece uma estrutura abstrata de parâmetros (valores) fonéticos apropriados para a expressão do output físico da fala. A representação (12), do ingliding em bid, conforma-se a essa concepção:

(12) Representação em tiers do ingliding em bid

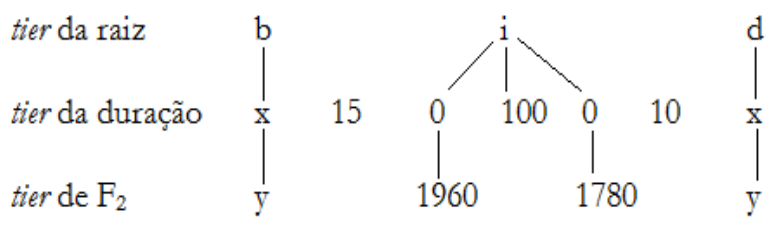

Ao tier da raiz associa-se o tier da duração e, a esse, o de $\mathrm{F}_{2}$, parâmetro relevante para medir o ingliding, conforme observado por Labov, Ash e Boberg 
(2006). Tanto no tier da duração como no de $F_{2}$, constam apenas as informações relevantes à realização vocálica. A duração da emissão vocálica é de $100 \mathrm{~ms}$. Os intervalos de 15 e $10 \mathrm{~ms}$ correspondem às transições entre consoante e vogal e entre vogal e consoante seguinte. Os zeros são sinalizadores (placeholders, em inglês) de duração zero posicionados à esquerda e à direita do fone no tier da duração, para fornecer a posição a que se ligam os valores-alvo de $\mathrm{F}_{2}$. Esses, no tier de $\mathrm{F}_{2}$, mostram que, na emissão com ingliding da vogal curta de bid, há redução de $\mathrm{F}_{2}$, indicando centralização na porção final da realização vocálica.

É importante observar que, no inglês, sistema que contrasta vogais curtas a longas e, as duas, a ditongos, a duração das vogais curtas como a de bid, com ou sem ingliding, é igual. $\mathrm{Na}$ análise que fizemos da ocorrência ibope sem e com a realização vocálica ditongada, verificamos aumento da duração no segundo caso. Talvez isso se deva ao fato de que, em português, a duração não é contrastiva, resultando no aumento de duração na realização ditongada. De qualquer forma, o que chama atenção na abordagem e análise de Clements e Hertz (1996) é o exercício da hipótese já empregada por Bisol (1989, 1996, 2012) na concepção dos ditongos derivados (fonéticos ou falsos): eles são representados por um só nó de raiz ligado a uma só posição esqueletal. $\mathrm{O}$ ingliding é fonético, não cria um novo fone, diferenciando essas realizações de vogais longas e ditongos (não-derivados ou verdadeiros), no caso do inglês.

Na hipótese de Bisol, principalmente no trabalho de 2012, a ideia é a de que a ditongação que cria ditongos falsos ou derivados, assimilatória, é, como vimos, a criação de um glide por expansão do nó CO. O ingliding, descrito por Labov, Ash e Boberg (2006) e representado por Clements e Hertz (1996), não cria um glide, mas resulta numa realização ditongada pela mudança na configuração formântica na porção final da emissão vocálica. Assim, pela análise que fizemos e considerando-se o que foi observado por todos esses autores, entendemos que a realização vocálica investigada, caracterizadora do português falado por portoalegrenses, (i) resulta numa emissão ditongada, mas não é ditongação (assimilatória), nos termos de Bisol, porque não se cria um novo fone (um glide); (ii) resulta numa emissão ditongada porque as vogais tônicas, especialmente em final de frase ou enunciado, sofrem alteração em seu padrão formântico: aumento de $F_{1}$ (abaixamento vocálico) e alterações de $F_{2}$, resultando na centralização da porção final, o que é característico do processo fonético de ingliding. (iii) $\mathrm{O}$ ingliding variável decorre do aumento de duração da emissão vocálica, o que vale dizer que muitas das emissões podem ser alongadas, mas não sofrer ingliding. (iv) De Bisol, mantém-se a ideia fundadora de que essas vogais correspondem a um só segmento na representação subjacente. 


\section{Conclusão}

Neste artigo, discutimos uma das contribuições de Leda Bisol à pesquisa sobre fonologia do português, qual seja, a proposta da existência de verdadeiros e falsos ditongos (BISOL, 1989, 1994, 2012), para definir se a alteração vocálica variável de vogais tônicas, caracterizadora do falar de Porto Alegre, poderia ser considerada ditongação.

A revisão sugeriu que as realizações ditongadas em estudo (né néah, aí aíah, tudo tuahdo) seriam compatíveis com a hipótese de Bisol de que ditongos falsos ou derivados, em termos de representação subjacente, corresponderiam a um só segmento. Já a análise (oitiva) de entrevistas sociolinguísticas com informantes de Porto Alegre, por meio do VARSUL, descartou a ideia de que fossem realizações ditongadas por assimilação, como as que Bisol abordou, porque não se identificou um contexto fonológico em que as realizações predominassem.

A análise acústica de realizações de uma falante prototípica revelou que há um aumento de duração nas formas em que a realização ditongada emerge. Mostrou também que há centralização da porção final da realização vocálica, o que é compatível com ingliding. Além disso, há abaixamento nessa porção final, o que resulta em [e] e confirma a intuição dos falantes-ouvintes de que se trate de um "a". A representação do ingliding integrando Fonologia e Fonética, conforme Clements e Hertz (1996), permitiu mostrar que o processo não é a criação de um glide, tal qual na ditongação assimilatória descrita e analisada por Bisol. Trata-se de um outro fenômeno, o ingliding. Ainda assim, a hipótese de Bisol aplica-se a esse processo, no sentido de que a realização ditongada resulta de apenas um segmento na subjacência.

A investigação, cujos primeiros passos foram relatados neste artigo, requer desenvolvimento. Está em andamento a análise acústica das demais vogais tônicas emitidas por nossa falante prototípica, com e sem a alteração vocálica em questão, com que se aumentará a quantidade e qualidade dos dados analisados, possibilitando assim verificar a variação formântica das vogais e a duração média de vogais não alongadas, alongadas e ditongadas. É preciso verificar a presença de coarticulação para, se sistemática, captar algum efeito assimilatório. Tudo isso feito, teremos condições de realizar estudos sociolinguísticos sobre as realizações vocálicas ditongadas no falar de Porto Alegre, pautados pela teoria fonológica e pelas hipóteses de Bisol, que vêm inspirando gerações de pesquisadores brasileiros.

\section{REFERÊNCIAS}

BISOL, L. O ditongo na perspectiva da fonologia atual. D.E.L.T.A., v.5, n.2, p. 186-224, 1989. 
. Ditongos derivados. D.E.L.T.A., v.10, n. Especial, p. 123-140, 1994.

. Ditongos derivados: um adendo. In: LEE, S-H. (Org.) Vogais além

de Belo Horizonte. Belo Horizonte: FALE/UFMG, p. 57-65, 2012.

CABREIRA, S. H. A monotongação dos ditongos orais decrescentes em Curitiba, Florianópolis e Porto Alegre. Dissertação (Mestrado em Letras). Programa de Pós-Graduação em Letras, Pontifícia Universidade Católica do Rio Grande do Sul. Porto Alegre - RS, 1996.

CLEMENTS, G. N. Place of articulation in consonants and vowels. Working papers of the Cornell Phonetics Laboratory, n.5, p. 78-115, 1991.

.; KEYSER, S. J. CV phonology: a generative view of the syllable. Cambridge: MIT Press, 1983.

.; HUME, E. The internal organization of speech sounds. In: GOLDSMITH, J. A. The Handbook of Phonological Theory. Cambridge, Mass.: Blackwell, 1995, p. 245-306.

.; HERTZ, S. R. An integrated approach to phonology and phonetics. In: DURAND, J.; LAKS, B. (Eds.) Current trends in phonology. Salford, Reino Unido: University of Salford Publications, 1996.

GOLDSMITH, J. A. Autosegmental phonology. Indiana: Indiana University, 1976.

HAYES, B. Introductory phonology. Malden/Oxford: Wiley-Blackwell, 2009.

HOUAISS, A.; VILlaR, M. de S. Dicionário Houaiss da Língua Portuguesa. Rio de Janeiro: Objetiva, 2009.

HULST, H. van der. Syllable structure and stress in Dutch. Dordrecht: Foris Publications, 1984.

LABOV, W. Sociolinguistic patterns. Philadelphia: University of Pennsylvania Press, 1972.

Principles of linguistic change - Cognitive and cultural factors. Malden/Oxford: Wiley-Blackwell, 2010.

.; ASH, S.; BOBERG, C. The Atlas of North American English (ANAE). Berlin/New York: Mouton The Gruyter, 2006.

LEIRIA, L. L. A ditongação variável em sílabas tônicas finais travadas por /S/. Dissertação (Mestrado em Letras). Programa de Pós-Graduação em Letras, Pontifícia Universidade Católica do Rio Grande do Sul. Porto Alegre RS, 1995.

MELLO, V. H. D. de. Formação de ditongo em sílaba travada por /S/ na fala coloquial gaúcha. Dissertação (Mestrado em Letras). Programa de PósGraduação em Letras, Universidade Federal do Rio Grande do Sul. Porto Alegre - RS, 1994.

SELKIRK, E. The syllable. In: HULST, H. van der; SMITH, N. (Eds.) The structure of phonological representations (part II). Dordrecht: Foris Publications, 1982, p. 337-383. 
SILVA, T. C. Dicionário de Fonética e Fonologia. São Paulo: Contexto, 2011.

TASCA, M. A inserção de glide em sílaba travada por /S/. Letras de Hoje, v.40, n.3, p. 167-132, 2005. 